\title{
Use of Potato Extract Broth for Culturing Root-Nodule Bacteria
}

\author{
STEFAN MARTYNIUK* and JADWIGA OROŃ \\ Department of Agricultural Microbiology, Institute of Soil Science and Plant Cultivation \\ - State Research Institute, Puławy, Poland
}

Received 1 September 2011, revised 29 September 2011, accepted 30 September 2011

\begin{abstract}
Liquid media containing potato extract and $1 \%$ of glucose or sucrose were used to culture root-nodule bacteria (rhizobia) in shaken Erlenmeyer flasks. For comparison, these bacteria were also cultured in yeast extract-mannitol broth (YEMB) as a standard medium. Proliferation of rhizobia was monitored by measuring optical densities $\left(\mathrm{OD}_{550}\right)$ of the cultures and by plate counting of the viable cells (c.f.u) of the bacteria. In general, multiplication of the rhizobia in potato extract-glucose broth (PEGB) and potato extract-sucrose broth (PESB) was markedly faster, as indicated by higher values of $\mathrm{OD}_{550}$, than in YEMB. The numbers of R. leguminosarum bv. vicae GGL and S. meliloti 330 in PEGB and PEGB were high and ranged from $1.2 \times 10^{10}$ to $4.9 \times 10^{10} \mathrm{~mL}^{-1}$ after $48 \mathrm{~h}$ of incubation at $28^{\circ} \mathrm{C}$. B. japonicum $\mathrm{B} 3 \mathrm{~S}$ culture in PEGB contained $6.4 \times 10^{9}$ c.f.u. $\mathrm{ml}^{-1}$ after $72 \mathrm{~h}$ of incubation. PEGB and YEMB cultures of the rhizobia were similar with respect to their beneficial effects on nodulation of the host-plants of these bacteria.
\end{abstract}

Ke y words: potato extract broth, proliferation, rhizobia

\section{Introduction}

Soil dwelling bacteria with the ability to form symbiotic relationships with leguminous plants (Fabaceae) belong to six genera: Allorhizobium, Azorhizobium, Bradyrhizobium, Mezorhizobium, Rhizobium and Sinorhizobiumj (Ensifer) and are commonly known as rhizobia or root-nodule bacteria (Vincent, 1981; Malek and Sajnaga, 1999; Willems, 2006). The most important feature of this symbiosis is fixation of atmospheric nitrogen by the bacteria, located inside root nodules, for the benefit of their host plants (Vincent, 1981; Kaminski et al., 1998). Inoculation of legume seeds or soils with commercial inoculants containing preselected strains of root-nodule bacteria is a common agriculture practice, which helps to ensure an effective symbiosis, particularly when natural soil populations of these bacteria are deficient, ineffective or only partially effective (Roughly, 1970; Stephens and Rask, 2000). The first step in the commercial production of rhizobial inoculants is mass culturing of the bacteria in a liquid medium, containing a cheap and complex source of nutrients. For example, yeast extract as a source of nitrogen, vitamins and other micronutrients is commonly used to prepare various media for culturing of rhizobia in research studies and for commercial purposes (Roughly, 1970; Vincent, 1981; Stephens and Rask, 2000). Many other substrates or industrial and agricultural by-product such as: proteolyzed pea husks (Gulati, 1979), corn steep liquor (Burton, 1979), malt extract (Bioardi and Ertola, 1985), cheese why (Bissonnette et al., 1986), or even wastewater sludge (Ben Rebah et al., 2007) have been proposed as media for rhizobial biomass production.

The aim of this work was to examine if potato extract can be used as a basic source of nutrients for cultivation of root-nodule bacteria in liquid cultures.

\section{Experimental}

\section{Material and Methods}

Root-nodule bacteria. The Culture Collection of $\mathrm{N}_{2}$-fixing Bacteria belonging to Department of Agricultural Microbiology of the Institute of Soil Sc. and Plant Cultivation in Pulawy was the source of the following species of rhizobia used in this work: Bradyrhizobium japonicum - strain B3S, Bradyrhizobium sp. (Lupinus) - strain LZ, Rhizobium leguminosarium bv. viciae - strain GGL and Sinorhizobium meliloti - strain 330. Stock cultures were maintained at $4^{\circ} \mathrm{C}$ on slants of yeast extract-mannitol agar (YEMA) supplemented with $3 \mathrm{~g} \mathrm{CaCO}_{3} \mathrm{~L}^{-1}$ (Vincent, 1981) and grown in yeast extract-mannitol broth (YEMB) as fresh starter cultures to inoculate experimental media.

\footnotetext{
* Corresponding autor: S. Martyniuk, Department of Agricultural Microbiology, Institute of Soil Science and Plant Cultivation - State Research Institute, 24-100 Puławy, Poland; phone: 488188634 21; fax: 48886 45 41; e-mail: sm@iung.pulawy.pl
} 
Preparation of potato extract. Glass bottle $(2 \mathrm{~L})$ containing $300 \mathrm{~g}$ of peeled potato tubers (cultivar Baszta), cut into smaller fragments, and $3 \mathrm{~g}$ of $\mathrm{CaCO}_{3}$ was poured with $1 \mathrm{~L}$ of tap water and the content was boiled for $20 \mathrm{~min}$. After boiling the mixture was filtered through cheese cloth and the volume of the extract was adjust to $1 \mathrm{~L}$ with distilled water. To prepare potato extract broth (PEB) supplemented C sources glucose or sucrose at the rate of $10 \mathrm{~g} \mathrm{~L}^{-1}$ of the filtered extract were added. For incubation experiments sets of $250 \mathrm{~mL}$ Erlenmeyer flasks containing $50 \mathrm{~mL}$ of PEB supplemented with glucose (PEGB) or sucrose (PESB) were prepared and autoclaved at $110^{\circ} \mathrm{C}$ for $20 \mathrm{~min}$. After autoclaving these media had $\mathrm{pH} 6.7-6.8$. When clear PEB media were needed, e.g. for measuring of optical densities (OD) of cultures larger volumes (e.g. $1.0 \mathrm{~L}$ ) of PEGB and PESB were prepared and after autoclaving the media were left on a laboratory bench for 24-48 hours to allow particles to settle. Portions $(50 \mathrm{~mL})$ of clear liquid from the upper layer was than aseptically distributed into sterile $250 \mathrm{~mL}$-Erlenmeyer flasks.

Incubation experiments. In the first experiment R. leguminosarium bv. viciae GGL and S. meliloti 330 were grown in potato extract - glucose broth (PEGB) and in potato extract-sucrose broth (PESB). B. japonicum B3S does not utilize sucrose (Jordan, 1984) and for this reason this species was cultured in PEGB only. For comparison yeast extract-glucose broth (YEMB) was also used to culture the bacteria. YEMB had the following composition $\left(\mathrm{g} \mathrm{L}^{-1}\right)$ : mannitol - 10; $\mathrm{K}_{2} \mathrm{HPO}_{4}$ - 0.5; $\mathrm{MgSO}_{4} \times 7 \mathrm{H}_{2} \mathrm{O}-0.2 ; \mathrm{NaCl}-0.1$; yeast extract (Difco) - 0.5 (Vincent, 1981). Flasks containing these media were inoculated with $2 \mathrm{~mL}$ of starter cultures of the rhizobia $\left(\mathrm{OD}_{550}=0.35-0.4\right)$ grown for $24 \mathrm{~h}$ in agitated YEMB at $28^{\circ} \mathrm{C}$. There were three replicated flasks for each of the rhizobial species and for each medium tested. The flasks were incubated at $28^{\circ} \mathrm{C}$ on a rotary shaker $\left(150 \mathrm{rev} \mathrm{min}^{-1}\right)$ and periodically $1 \mathrm{~mL}$ samples were withdrawn aseptically to measure optical densities of the cultures at $\lambda=550 \mathrm{~nm}\left(\mathrm{OD}_{550}\right)$.

In the second experiment the same media and incubation conditions was used but proliferation of rhizobia was monitored by determination of counts of viable rhizobial cells (colony forming units - c.f.u.) by dilution plating on Cong red-YEMA (Vincent, 1981). Colonies of the fast-growing and slow-growing rhizobia were counted after 3 and 7 days, respectively, of incubation at $28^{\circ} \mathrm{C}$.

In the third experiment shortly-boiled potato extractglucose broth (SB-PEGB) was used. This medium was prepared as described above with the exception of boiling time, which was shortened to 5 minutes. After autoclaving SB-PEGB had $\mathrm{pH}$ 6.8. Incubation and counting of rhizobial c.f.u were done as describe above.
Nodulation biotest with legumes. Rhizobial cultures obtained in the second experiment after 48 hours of incubation were used to inoculate seeds or seedlings of Medicago sativa L. (alfalfa) cv. Socza, Pisum arvense L. (field pea) cv. Grapis and Glycine max L. cv. Aldana, which were grown in sand pouches (Martyniuk et al., 2000). Shortly, in this biotest seedlings were grown in polypropylene pouches filled with sterile sand moistened with sterile $\mathrm{N}$-free nutrient solution to support plant growth. Before sowing the seeds were surface disinfected by soaking for $10 \mathrm{~min}$. in $5 \% \mathrm{H}_{2} \mathrm{O}_{2}$, followed by several rinses with sterile water. Two seeds of pea or soybean were sown into each pouch and inoculated with $1 \mathrm{~mL}$ of their respective rhizobial cultures grown on YEMB and PEGB (from Experiment 2). Disinfected seeds of alfalfa (lucerne) were pre-germinated on sterile $1 \%$ water agar at $25^{\circ} \mathrm{C}$ for 48 hours. Four uniform seedlings were than planted into each sand pouch and inoculated with $1 \mathrm{~mL}$ of $S$. meliloti 330 culture as above. Ten replicated sand pouches were prepared for each plant species and after emergence of seedling six pouches containing well developed and uniform seedlings were selected and placed in a growth chamber (Heresus HPS 1500-2000) running at $16 \mathrm{~h} / 8 \mathrm{~h}$ day/night regime and temperature $22^{\circ} \mathrm{C} / 15^{\circ} \mathrm{C}$, respectively. After four weeks the experiment was terminated and numbers of nodules on the root system of nodulating seedlings were counted.

Data were subjected to the analysis of variance using Anova test.

\section{Results}

In the first experiment two fast-growing rhizobial species: Rhizobium leguminosarum bv. viciae GGL and S. meliloti 330, and one slow-growing Bradyrhizobium japonicum $\mathrm{B} 3 \mathrm{~S}$ were used. Figure 1 shows that starting from 24 hours of incubation proliferation of S. meliloti 330 in potato-extract media (PEGB and PESB) was markedly faster, as indicated by higher values of $\mathrm{OD}_{550}$, than in YEMB. Similar results were obtained for R. leguminosarum bv. viciae GGL, though during the first 24 hours of incubation all cultures had comparable optical densities (Fig. 1). Slow-growing B. japonicum B3S does not metabolize sucrose, therefore growth of this rhizobial species was monitored for 72 hours only in potato medium enriched with glucose (PEGB) and compared with that in YEMB. As Figure 1 shows all cultures of B. japonicum B3S in PEGB, except that at $6 \mathrm{~h}$ of incubation, had significantly higher densities than those in YEMB.

This experiment was repeated, but since some rhizobial strains, e.g. GGL strain of R. leguminosarum bv. viciae tested in the first experiment, gave clumpy 


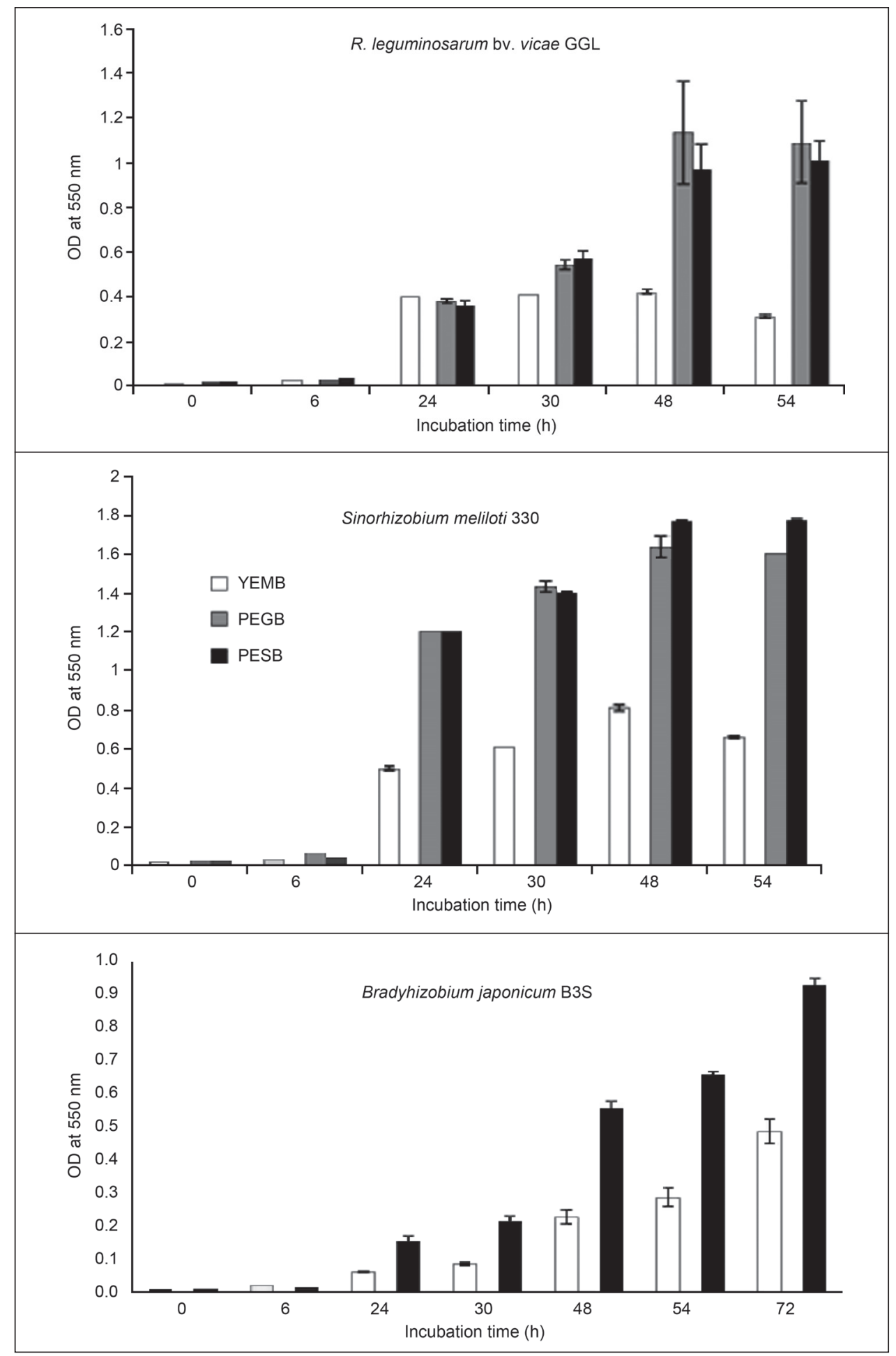

Fig. 1. Optical densities $\left(\mathrm{OD}_{550}\right)$ of rhizobial cultures grown in yeast extract-mannitol broth (YEMB), potato extract-glucose broth (PEGB) and in potato extract-sucrose broth (PESB) at various samplings during incubation at $28^{\circ} \mathrm{C}$.

Bars represent standard deviations of three measurements.

cultures resulting in a marked variability of OD measurements, particularly in the case of potato-extract media (Fig. 1), in the second experiment growth of the rhizobia was monitored by plate counting of viable cells (c.f.u) after 6, 24, 48 and 72 hours (in the case of B. japonicum B3S) of incubation. Results of this experiment, shown in Table I, agree well with those obtained in the previous experiment and indicate that the final cultures (after 48 of $72 \mathrm{~h}$ of incubation) of the rhizobia grown in PEGB and PESB contained, in general, significantly higher numbers of viable cells than those in YEMB. The numbers of viable cells (c.f.u) of the rhizobia in PEGB and PESB were high and ranged from $1.2 \times 10^{10}$ to $4.9 \times 10^{10} \mathrm{~mL}^{-1}$ in the case of the fast-growing 
Table I

Numbers of c.f.u. of rhizobia in yeast extract-mannitol broth (YEMB), potato extract-glucose broth (PEGB) and in potato extract-sucrose broth (PESB) after $6 \mathrm{~h}, 24 \mathrm{~h}$ and $48 \mathrm{~h}$ of incubation at $28^{\circ} \mathrm{C}$

\begin{tabular}{|l|c|c|c|c|}
\hline \multirow{2}{*}{$\begin{array}{c}\text { Me- } \\
\text { dium }\end{array}$} & 6 & 24 & 48 & 72 \\
\cline { 2 - 5 } & 6 & Incubation time $(\mathrm{h})$ \\
\hline YEMB & $2.3 \times 10^{8} \mathrm{a}^{*}$ & $3,3 \times 10^{9} \mathrm{a}$ & $1.6 \times 10^{10} \mathrm{a}$ & n.a R $^{* *}$ \\
\hline PEGB & $2.5 \times 10^{8} \mathrm{a}$ & $3.0 \times 10^{9} \mathrm{a}$ & $4.9 \times 10^{10} \mathrm{~b}$ & n.a \\
\hline PESB & $3.0 \times 10^{8} \mathrm{a}$ & $3.7 \times 10^{9} \mathrm{a}$ & $1.2 \times 10^{10} \mathrm{a}$ & n.a. \\
\hline \multicolumn{5}{|c|}{ Sinorhizobium meliloti 330} \\
\hline YEMB & $4.5 \times 10^{8} \mathrm{a}$ & $1.6 \times 10^{9} \mathrm{a}$ & $1.9 \times 10^{9} \mathrm{a}$ & n.a. \\
\hline PEGB & $4.4 \times 10^{8} \mathrm{a}$ & $2.5 \times 10^{10} \mathrm{~b}$ & $1.5 \times 10^{10} \mathrm{~b}$ & n.a. \\
\hline PESB & $3.0 \times 10^{8} \mathrm{a}$ & $2.1 \times 10^{10} \mathrm{~b}$ & $3.3 \times 10^{10} \mathrm{c}$ & n.a. \\
\hline \multicolumn{6}{|c|}{ Bradyrhizobium japonicum $\mathrm{B} 3 \mathrm{~S}$} \\
\hline YEMB & $2.7 \times 10^{7} \mathrm{a}$ & $1.4 \times 10^{8} \mathrm{~b}$ & $1.4 \times 10^{9} \mathrm{a}$ & $3.2 \times 10^{9} \mathrm{a}$ \\
\hline PEGB & $2.7 \times 10^{7} \mathrm{a}$ & $1.3 \times 10^{8} \mathrm{~b}$ & $1.3 \times 10^{9} \mathrm{a}$ & $6.4 \times 10^{9} \mathrm{~b}$ \\
\hline
\end{tabular}

* numbers of particular rhizobial species within any one incubation time with the same letters are not significantly different $(p=0.05)$

** not analyzed

rhizobia after $48 \mathrm{~h}$ of incubation (Table I). PEGB culture of B. japonicum B3S contained $6.4 \times 10^{9}$ c.f.u. $\mathrm{mL}^{-1}$ after $72 \mathrm{~h}$ of incubation (Table I).

In the third incubation experiment shortly-boiled potato extract enriched with glucose (SB-PEGB) was used to grow S. meliloti 330 and two species of Bradyrhizobium, B.japonicum B3S and Bradyrhizobium sp. (Lupinus), strain LZ. All the rhizobia tested in this experiment grew in the shortly-boiled PEGB medium equally well, or even better, than in PEGB used in the
Table II

Numbers of c.f.u. of rhizobia in shortly-boiled potato extract-glucose broth (SB-PEGB) after $6 \mathrm{~h}, 24 \mathrm{~h}, 48 \mathrm{~h}$ and $72 \mathrm{~h}$ of incubation at $28^{\circ} \mathrm{C}$

\begin{tabular}{|c|c|c|c|}
\hline \multicolumn{4}{|c|}{ Incubation time (h) } \\
\hline 6 & 24 & 48 & 72 \\
\hline \multicolumn{4}{|c|}{ Sinorhizobium meliloti 330} \\
\hline $3.0 \pm 0.1 \times 10^{9^{*}}$ & $3.6 \pm 0.2 \times 10^{10}$ & $3.2 \pm 0.7 \times 10^{11}$ & $2.8 \pm 0.4 \times 10^{11}$ \\
\hline \multicolumn{4}{|c|}{ Bradyrhizobium japonicum B3S } \\
\hline $1.1 \pm 0.1 \times 10^{8}$ & $3.4 \pm 0.3 \times 10^{9}$ & $3.2 \pm 0.4 \times 10^{10}$ & $4.6 \pm 0.5 \times 10^{10}$ \\
\hline \multicolumn{4}{|c|}{ Bradyrhizobium sp. (Lupine) LZ } \\
\hline $4.3 \pm 0.2 \times 10^{8}$ & $7.9 \pm 0.8 \times 10^{9}$ & $4.1 \pm 0.2 \times 10^{10}$ & $2.0 \pm 0.4 \times 10^{10}$ \\
\hline
\end{tabular}

* Numbers of rhizobia $\pm \mathrm{SD}$ (standard deviation) of three measurements

first two experiments. For example, SB-PEGB cultures of S. meliloti 330 and B. japonicum B3S after $48 \mathrm{~h}$ of incubation contained about 10-fold higher numbers of c.f.u. than the cultures of these bacteria in PEGB used in the first experiment (Tables I and II). Proliferation of Bradyrhizobium sp. (Lupine) LZ in SB-PEGB was slower than B.japonicum B3S, particularly after $24 \mathrm{~h}$ and $48 \mathrm{~h}$ of incubation, but in the final culture (after $72 \mathrm{~h})$ a high population $\left(2.0 \times 10^{10}\right)$ of the lupine microsymbiont c.f.u. was found (Table II). In shortly-boiled PEGB the highest numbers of S. meliloti 330, $3.2 \times 10^{11}$ c.f.u. $\mathrm{mL}^{-1}$, were detected after $48 \mathrm{~h}$ of incubation. The SB-PEGB cultures of the slow-growing rhizobia (R. japnicum B3S and B. sp (Lupinus) LZ) contained $2-4.6 \times 10^{10}$ c.f.u. $\mathrm{mL}^{-1}$ after $72 \mathrm{~h}$ of growth (Tables II).

In the nodulation biotest seedlings of alfalfa, pea and soybean were inoculated with cultures of their specific symbiotic bacteria, S. meliloti 330, R. legumi-

Table III

Nodulation of legumes 4 weeks after their seed inoculation with $48 \mathrm{~h}$ old cultures of respective rhizobia (Experiment 2) grown in yeast extract-glucose broth (YEGB) and in potato extract-glucose broth (PEGB)

\begin{tabular}{|c|c|c|}
\hline Seed treatment & $\begin{array}{c}\text { Percentage of plants } \\
\text { with nodules }\end{array}$ & $\begin{array}{c}\text { Number of nodules } \\
\text { per plant }\end{array}$ \\
\hline \multicolumn{3}{|c|}{ Alfalfa (Medicago sativa L.) } \\
\hline Non-inoculated seeds & 80 & $1.2 \mathrm{a}^{\star}$ \\
\hline Inoculated with YEMB culture of $S$. meliloti & 100 & $2.3 \mathrm{~b}$ \\
\hline Inoculated with PEGB culture of $S$. meliloti & 100 & $2.1 \mathrm{~b}$ \\
\hline \multicolumn{3}{|c|}{ Pea ( Pisum arvense L.) } \\
\hline Non-inoculated seeds & 50 & $7.9 \mathrm{a}$ \\
\hline Inoculated with YEMB culture of $R . l$. bv. viciae & 100 & $23.7 \mathrm{~b}$ \\
\hline Inoculated with PEGB culture of $R$. l. bv. viciae & 100 & $23.9 \mathrm{~b}$ \\
\hline \multicolumn{3}{|c|}{ Soybean (Glycine max L.) } \\
\hline Non-inoculated seeds & 0 & $0.0 \mathrm{a}$ \\
\hline Inoculated with YEMB culture of B. japonicum & 100 & $6.5 \mathrm{~b}$ \\
\hline Inoculated with PEGB culture of B. japonicum & 100 & $5.6 \mathrm{~b}$ \\
\hline
\end{tabular}

* Numbers of nodules on roots of particular plant species with the same letter are not significantly different $(\alpha=0.05)$ 
nosarum bv. viciae GGL and B. japonicum B3S, respectively, grown for $48 \mathrm{~h}$ in YEMB and PEMB (Experiment 2) in order to compare nodulating ability of these cultures. It was found that both cultures were similar with respect to their beneficial effects on nodulation of all the host-plants of the rhizobia used in this experiments (Table III).

\section{Discussion}

Commercially available potato extract-dextrose agar (PDA) medium is commonly applied to culture various saprophytic and plant pathogenic fungi (Hawksworth et al., 1995; Sharma and Pandey, 2010) and the results of our experiments indicate that potato extract based broth can also be used for successful cultivation rootnodule bacteria, as the numbers of all the rhizobial species cultured in PEGB or PESB were, in general, significantly higher than those grown in the reference YEMB, particularly at the end of the incubation period (Tables I and II). Cultures of the fast-growing species of the rhizobia, R. leguminosarum bv. viciae GGL and S. meliloti 330, that we tested in our experiments, reached their late log phase (the highest $\mathrm{OD}_{550}$ values) usually after $48-54 \mathrm{~h}$ of incubation (Fig. 1), but the slow-growing Bradyrhizobium species required a longer incubation period, similarly to results reported earlier (Roughly, 1970; Burton, 1979; Ben Rebah et al., 2007). The numbers of the viable cells (c.f.u) of the rhizobia in PEGB and PESB accounted for $1.2 \times 10^{10}$ to $4.9 \times 10^{10} \mathrm{~mL}^{-1}$ in the case of the fast-growing rhizobia and $6.4 \times 10^{9}$ c.f.u ml ${ }^{-1}$ in the case of B. japonicum B3S, (Table I) were comparable or higher than those obtained in other studies on culturing of the rootnodule bacteria in various liquid media (Gulati, 1979; Bioardi and Ertola, 1985; Bissonnette et al., 1986; Ben Rebah et al., 20007). It has been found that the composition of growth media can have a significant effect on some characteristics of rhizobia. For instance, high concentrations of yeast extract $\left(>3.5 \mathrm{~g} \mathrm{~L}^{-1}\right)$ in liquid media can decrease nodulation potential of root-nodule bacteria grown in such media (Bissonnette et al., 1986; Stephens and Rask, 2000). For this reason nodulation of alfalfa, pea and soybean seedlings inoculated with the cultures of their specific rhizobia grown in PEGB and in YEMB was compared (Table III). This experiment has shown that both cultures of the rhizobia had similar effectiveness with respect to their effect on nodulation of the legumes. Thus, the use of potato extract based media for the proliferation root-nodule bacteria seems to be safe with respect to the preservation of their infectivity and ability to induce nodules on roots of the host plants. Relatively high percentages of nodulating alfalfa and pea seedlings found in the control (non- inoculated) treatment (Table III) were connected with rather a mild seed sterilizing agent $\left(5 \% \mathrm{H}_{2} \mathrm{O}_{2}\right)$ that we used in this experiment. Some legume seeds, e.g. alfalfa, are particularly difficult to disinfect (Vincent, 1981).

In the shortly-boiled PEGB the numbers of the tested rhizobial strains were markedly higher than in PEGB, reaching $3.2 \times 10^{11}$ c.f.u. $\mathrm{mL}^{-1}$ in the case of S. meliloti 330 and $2-4.6 \times 10^{10}$ c.f.u. $\mathrm{mL}^{-1}$ in the case of the slow-growing rhizobia (Tables II), indicating that short boiling ( $5 \mathrm{~min}$ ) is not only an energy-saving treatment but also is probably less destructive for some growth factors, e.g. vitamins, than longer boiling $(20 \mathrm{~min})$. Moreover, it seems that, after separating the extract for culturing of microorganisms, shortly boiled (blanched) potato fragments could be used for other purposes, e.g. as frozen consumption product.

\section{Literature}

Ben Rebah F., D. Prevost, A. Yezza and R.D. Tyagi. 2007. Agroindustrial waste materials and wastewater sludge for rhizobial inoculants production: A review. Bioresource Tech. 98(18): 3535-3546.

Bioardi J.L. and R.J. Ertola. 1985. Rhizobium biomass production in batch and continuous culture with a malt-sprouts medium. Mircen. J. 1: 163-171.

Bissonnette N., R. Lalande and L.M. Bordeleau. 1986. Large-scale production of Rhizobium meliloti on whey. Appl. Environ. Microbiol. 52: 838-841.

Burton J.C. 1979. Rhizobium species, pp. 29-58. In: Peppler H.J., Perlman D. (eds.), Microbial Technology, Academic Press, New York. Gulati S.J. 1979. New non synthetic medium for Rhizobium culture production from wastes. Biotechnol. Bioeng. 21: 1507-1515.

Hawksworth D.L., P.M. Kirk, B.C. Sutoon and D.N. Pegler. 1995. Ainisworth \& Bishby's Dictionary of the Fungi, CAB International, Cambridge.

Jordan D.C. 1984. Family III Rhizobiaceae, pp. 234-244. In: Kneg N.R., Holt J.G. (eds), Bergey's Manual of Systematic Bacteriology, Vol. 1. Williams and Wilkins, Baltimore.

Kaminski P.A., J. Batut and P. Boistard. 1998. A survey of symbiotic nitrogen fixation by rhizobia, pp. 431-460. In: Spaink H.P., A. Kondorosi and P.J.J. Hooykaas (eds.), The Rhizobiaceae, Kluwer Acad. Pub., Dordrecht.

Malek W. and E. Sajnaga. 1999. Current taxonomy of the rhizobia, Acta Microbiol. Polon. 48: 109-122.

Martyniuk S., A. Woźniakowska, M. Martyniuk and J. Oroń. 2000. A new sand pouch-plant infection technique for enumeration of rhizobia in soil. Acta Soc. Botanic. Poloniae 69: 1-5.

Roughley R.J. 1970. The preparation and use of legume seed inoculants. Plant and Soil 32: 675-701

Sharma G. and R.R. Pandey. 2010. Influence of culture media on growth, colony character and sporulation of fungi isolated from decaying vegetables wastes, J. Yeast Fungal Res. 1: 157-164.

Stephens J.H.G. and H.M. Rask. 2000. Inoculant production and formulation. Field Crop Res. 65: 249-258.

Vincent J.M. 1981. The genus Rhizobium, pp. 819:841. In: Starr M.P., H. Stolp, H.G. Truper., A. Balows and H.G. Schlegel (eds.), The prokaryotes - a handbook on habitats, isolation and identification of bacteria, Springer-Verlag, Berlin Heidelberg New York.

Willems A. 2006. The taxonomy of rhizobia: an overview, Plant and Soil 287: 3-14. 